\title{
Seismic multi-attribute analysis for petrophysics reservoir prediction with probabilistic neural network in "FA" field
}

\author{
Fadlan Ardinda* and Agus Riyanto \\ Geophysics, Faculty of Mathematics and Natural Sciences, Universitas Indonesia
}

\begin{abstract}
Oil and gas reserves are increasingly difficult to find due to more complex geological conditions. This complex condition causes difficulties in determining reservoir distribution. Therefore, a better method is needed to overcome these complex geological conditions. In this study, the petrophysics analysis by using the multi-attribute and the Probabilistic Neural Network (PNN) used to make reservoir distribution model on seismic horizontal slice. This multi-attribute method and Probabilistic Neural Network (PNN) that can search for correlation between seismic attributes and the data sought, for the prediction of property values from surrounding rocks. From this method, the distribution of porosity data with a correlation value of 0.52 was generated, water saturation with a correlation value of 0.73 , and shale content with a correlation value of 0.58 . Where the combination of porosity data, water saturation, shale content, and acoustic impedance (AI) data of inversion results can be a clue to identify reservoir distribution. From the porosity and saturation values, hydrocarbon dispersion can be made, wherein this study values were obtained between $0.01-0.03$. This "FA" field has a reservoir between wells F-06, FA-05, FA-15, and FA-18 and spreads westward from wells FA-05, FA-15 \& FA-18. The distribution of petrophysical parameters generated from the validation of well data using the multi-attribute method. This thing prove that Multi-attribute and neural network analysis can be used to determine predictions of porosity, water saturation, and shale content well and can be used for reservoir characterization.
\end{abstract}

\section{Introduction}

Energy needs in oil and gas every year continues to increase, while the discovery of new oil and gas reserves is still very little. This caused Indonesia to no longer be an exporter and left OPEC. That way exploration in the search for hydrocarbon energy is still very much needed. On the other hand, oil and gas reserves are also increasingly difficult to find because of more complex geological conditions. Therefore, a better method is needed to overcome these complex geological conditions. The reservoir characterization method is still the method used by companies in oil and gas exploration. To do this reservoir characterization, several methods are needed, in which the results will become a conceptual model of the reservoir so that we can determine the reservoir zone.

In this study, a multi-attribute analysis will be performed to predict petrophysical analysis. Multiattribute analysis can predict the value of petrophysical parameters with a very small error rate [1]. The parameter values predicted from the multi-attribute analysis are shale content, porosity, and water saturation. This analysis is also assisted by the Probabilistic neural network (PNN) method which is used to distribute the value of the seismic multi-attribute results so as to reduce its error rate [2]. After that, the correlation and validation results will be seen between the estimated value of the neural network and the actual value to see the error value. Neural network applications also help detect the distribution of these parameters in the seismic section, thus helping to identify reservoirs that are below the surface [2]. From the porosity and water saturation data, hydrocarbon data distribution can be made, which will help determine reservoir determination.

In this study, the petrophysics analysis by using the multi-attribute and the Probabilistic Neural Network (PNN) used to make reservoir distribution model on seismic horizontal slice.

\section{South Sumatra geological setting}

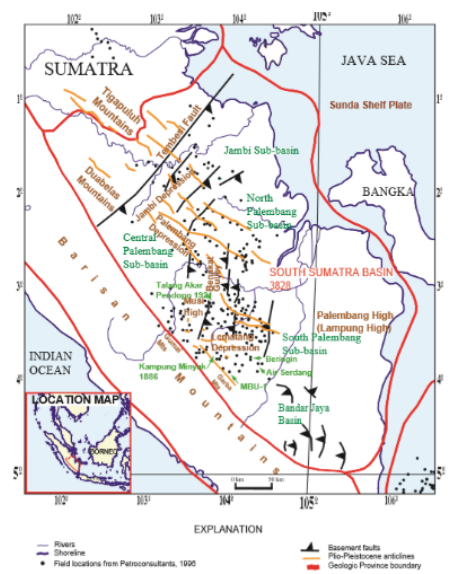

Fig. 1. Study area in Jambi sub-Basin in a red box modified from Bishop (2001) [3]

The study area was carried out in the Jambi Sub-Basin which is part of the South Sumatra Basin. The South Sumatra Basin was formed from the rifting process due to extensional forces that occurred during the Eocene. Graben and major faults in the South Sumatra Basin are north-northwest to south-southeast oriented (Bishop,

\footnotetext{
*Corresponding author: fadlan.ardinda@ui.ac.id
} 
2001). The South Sumatra Basin is bounded by The Bukit Barisan in the west, Tigapuluh High in the north, Lampung High in the south, and Sunda Exposure in the east (Figure 1). The Jambi sub-basin is a series of Paleogene-aged northeast-southwest trending halfgrabens.

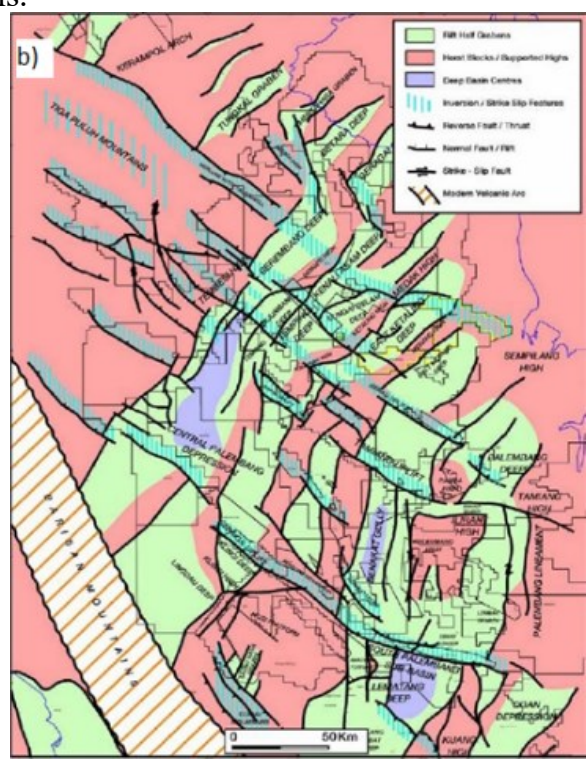

Fig. 2 Element structural map which dominated by NW-SE orientation [4]

Regional stratigraphy in the South Sumatra Basin is composed of Rock Base, Lemat Formation, Lahat Formation, Talang Akar Formation, Baturaja Formation, Gumai Formation, Air Benakat Formation, Muara Enim Formation and Kasai Formation. This study targeting on the Air Benakat formation,

\section{Materials and methodology}

To create a reservoir characterization model, it is necessary to characterize the reservoir structure and the contents contained in the reservoir. This requires some help data, such as Well, Seismic, and Checkshot data. The coverage area of the seismic data and the wells used is shown in Figure 3

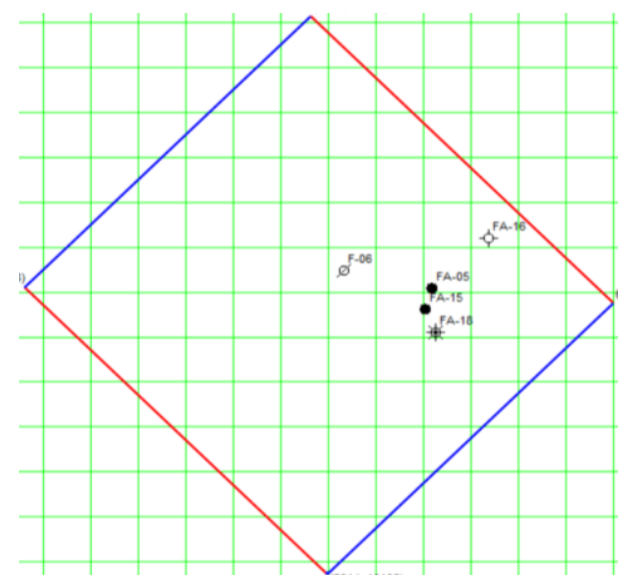

Fig. 3 Base Map on "FA" Field
There are 5 well data used, all of them have log data needed for this study, such as gamma-ray log, porosity, density, resistivity, and p-wave. Then, this study also added a petrophysics log consisting of water saturation, shale content, and porosity. From this data we can determine which formations are the target of the formation, then petrophysics distribution will be carried out in all seismic areas to obtain 3D models.

Table 1. Well Data in the Research Area

\begin{tabular}{|c|c|c|c|c|c|}
\hline Data Sumur & $\begin{array}{l}\text { F- } \\
06\end{array}$ & $\begin{array}{c}\text { FA- } \\
05\end{array}$ & $\begin{array}{c}\text { FA- } \\
15\end{array}$ & $\begin{array}{c}\text { FA- } \\
16\end{array}$ & $\begin{array}{c}\text { FA- } \\
18\end{array}$ \\
\hline GR & $\mathrm{V}$ & $\mathrm{V}$ & $\mathrm{V}$ & $\mathrm{V}$ & $\mathrm{V}$ \\
\hline $\mathrm{SP}$ & $\mathrm{V}$ & $\mathrm{V}$ & $\mathrm{V}$ & $\mathrm{V}$ & $\mathrm{V}$ \\
\hline Resistivity & $\mathrm{V}$ & $\mathrm{V}$ & $\mathrm{V}$ & $\mathrm{V}$ & $\mathrm{V}$ \\
\hline Checkshot & $\mathrm{V}$ & $\mathrm{V}$ & $\mathrm{V}$ & $\mathrm{V}$ & $\mathrm{V}$ \\
\hline RHOB & $\mathrm{V}$ & $\mathrm{V}$ & $\mathrm{V}$ & $\mathrm{V}$ & $\mathrm{V}$ \\
\hline NPHI & $\mathrm{V}$ & $\mathrm{V}$ & $\mathrm{V}$ & $\mathrm{V}$ & $\mathrm{V}$ \\
\hline P-Wave & $\mathrm{V}$ & $\mathrm{V}$ & $\mathrm{V}$ & $\mathrm{V}$ & $\mathrm{V}$ \\
\hline $\begin{array}{l}\text { Total } \\
\text { Porosity }\end{array}$ & $\mathrm{v}$ & $\mathrm{V}$ & $\mathrm{V}$ & $\mathrm{V}$ & $\mathrm{V}$ \\
\hline $\begin{array}{l}\text { Effective } \\
\text { Porosity }\end{array}$ & $\mathrm{V}$ & $\mathrm{V}$ & $\mathrm{v}$ & $\mathrm{V}$ & $\mathrm{V}$ \\
\hline Saturasi Air & $\mathrm{v}$ & $\mathrm{v}$ & $\mathrm{v}$ & $\mathrm{v}$ & $\mathrm{v}$ \\
\hline Konten Shale & $\mathrm{V}$ & $\mathrm{V}$ & $\mathrm{V}$ & $\mathrm{V}$ & $\mathrm{V}$ \\
\hline
\end{tabular}

Well to Seismic Tie is a process to tie well data that has depth domain with seismic data that has time domain. This step is needed so the target horizon that has been determined from well data can be adjusted in seismic data, because well data have higher vertical resolution than seismic data. The process will be made a synthetic seismogram that will be correlated with the original seismic. Synthetic seismograms are the result of the convolution between wavelets and the reflection coefficient.

From the results of the well to seismic tie data, the well marker will appear in the seismic data, the marker that determines the line horizon which is the target zone. In this study, the picking process was carried out in Petrel 2015 software. The picking process was carried out on the $\mathrm{M}, \mathrm{N}$, and $\mathrm{O}$ horizons. The picking horizon and fault processes in Xline and Inline are shown in Figure 4 and Figure 5. 


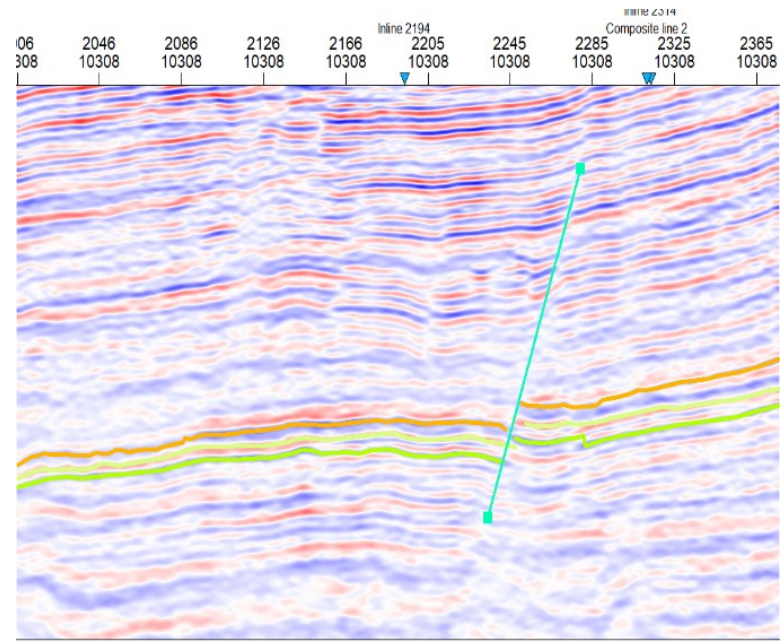

Fig. 4. Picking Horizon and Fault on Xline 10308

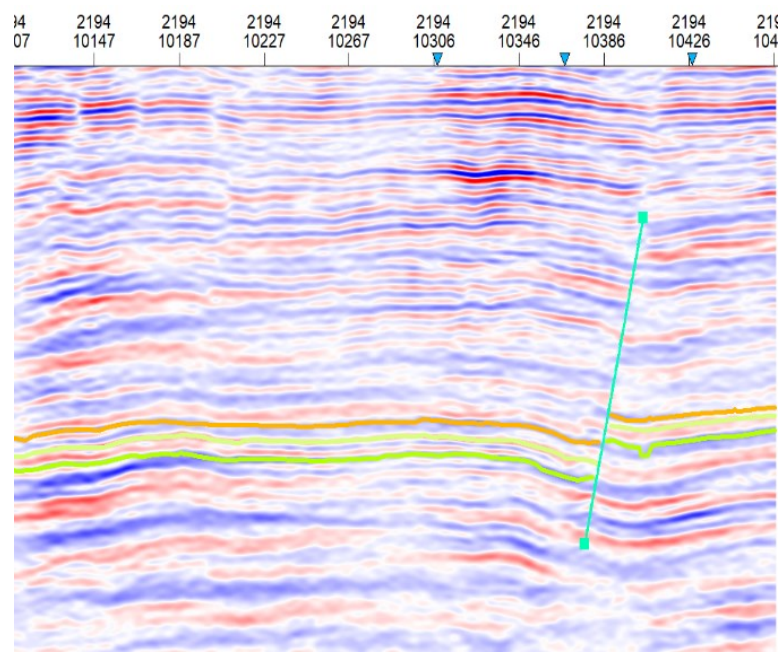

Fig. 5. Picking Horizon and Fault on Inline 2194

The picking process uses an increment of 20 on the Inline \& Xline, and uses structural smoothing assistance to clarify the reflector plane of the seismic so that the continuity of the horizon looks better and clearer. After the horizon and fracture picking completed, a surface map of the picking results are made on each horizon. Examples of surface map results on horizon $M$ can be seen in (Figure 6), Examples of surface map results on horizon $\mathrm{N}$ can be seen in (Figure 7), Examples of surface map results on horizon $\mathrm{O}$ can be seen in (Figure 8).

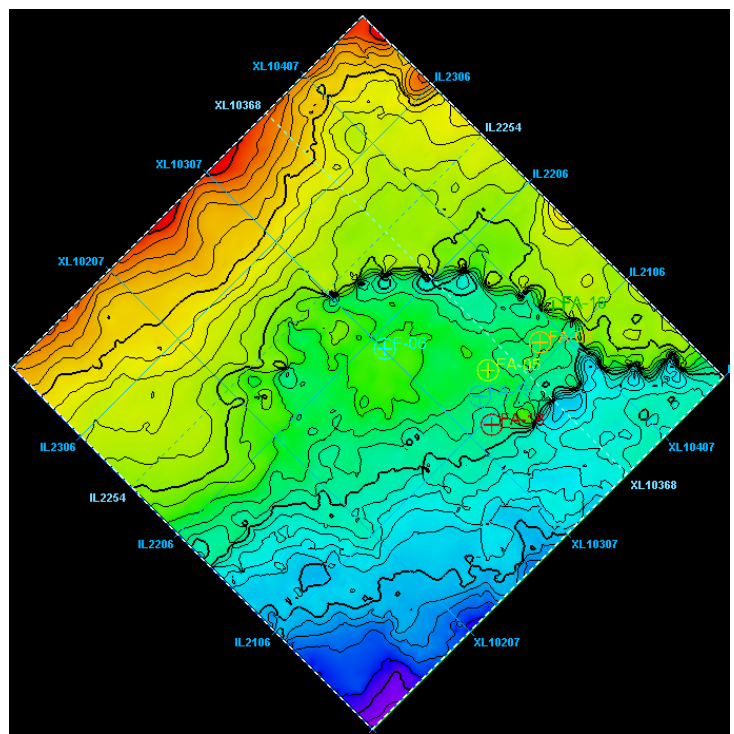

Fig. 6. Surface Map from Horizon M

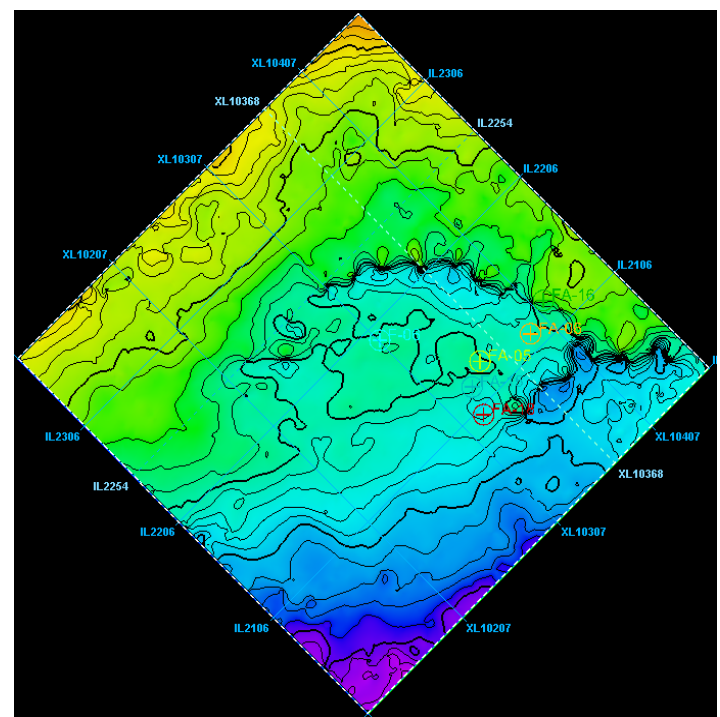

Fig. 7. Surface Map from Horizon N

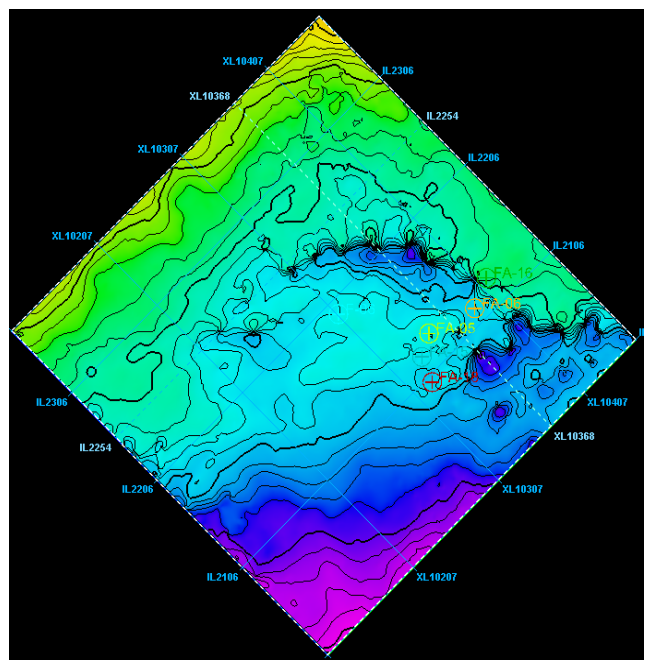

Fig. 8. Surface Map from Horizon O

Inversion is a process that is also needed to spread well data on seismic maps. Inversion is a deconvolution process to see the reflection coefficient data of our seismic trace, because we want to see the boundary 
plane of the bedding more clearly. At this inversion stage, we need to find the value of the impedance and after getting the value of the impedance we can get the value of the reflection coefficient. Where the formula of impedance is density multiplied by speed. Then, the acoustic impedance results will be modeled. After that the inversion based model will be made so the model that appears will be more visible in its boundary fields. Then it will be continued with inversion, in this study the inversion process is limited to the $800-1600 \mathrm{~ms}$ window which is the target zone and uses wavelets from well F-06. The results of the inversion analysis showed the results ranged from 0.9 (Figure 14) and the error results ranged from 600 to 1800 . From the inversion results, it is similar to the original well data. The results of inversion analysis on F-06, FA-05, FA-15, FA-16, and FA-18 wells can be seen in Figure 9 - Figure 13. Then, if the analysis is good, the inversion Model Based will be made.

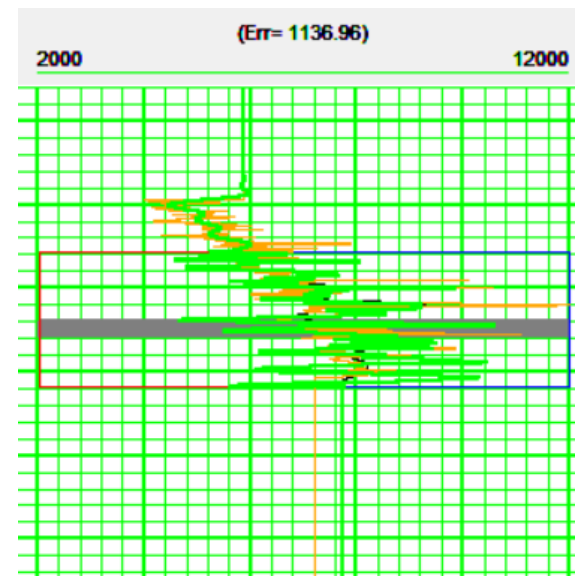

Fig. 9. Results of Inversion Analysis from Well F-06

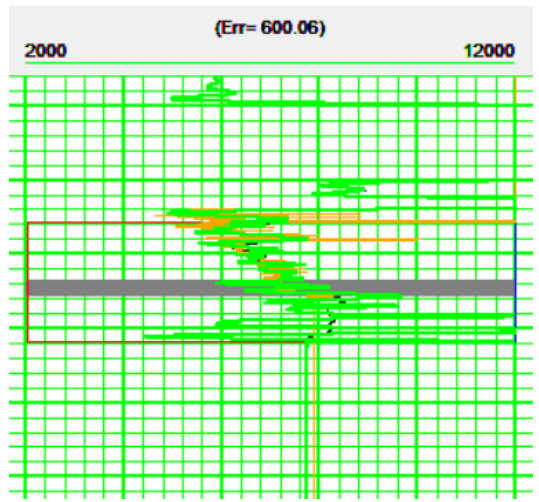

Fig. 10. Results of Inversion Analysis from Well FA-05

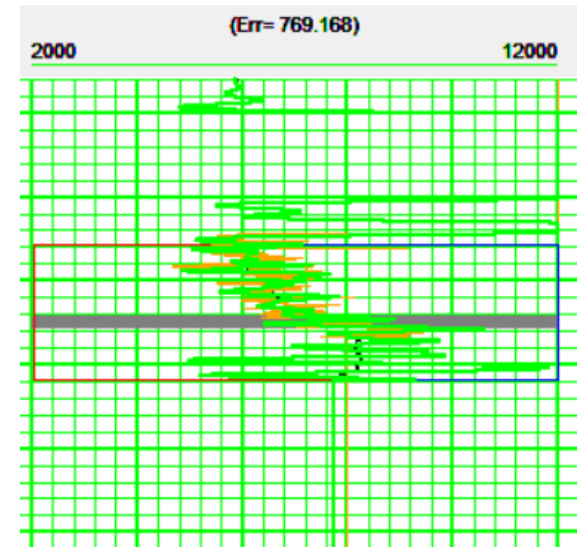

Fig. 11. Results of Inversion Analysis from Well FA-15

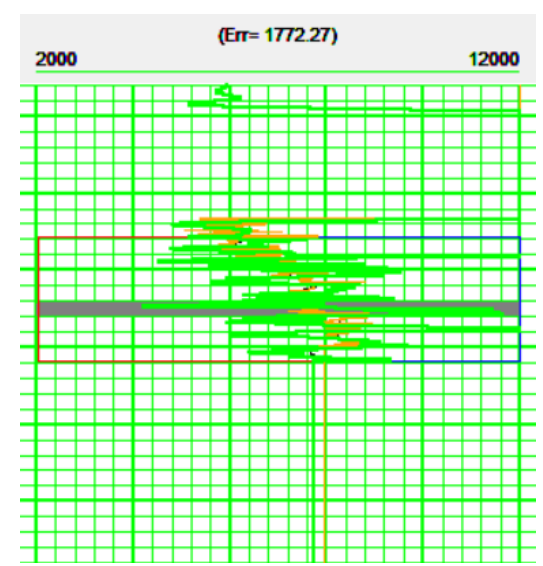

Fig. 12. Results of Inversion Analysis from Well FA-16

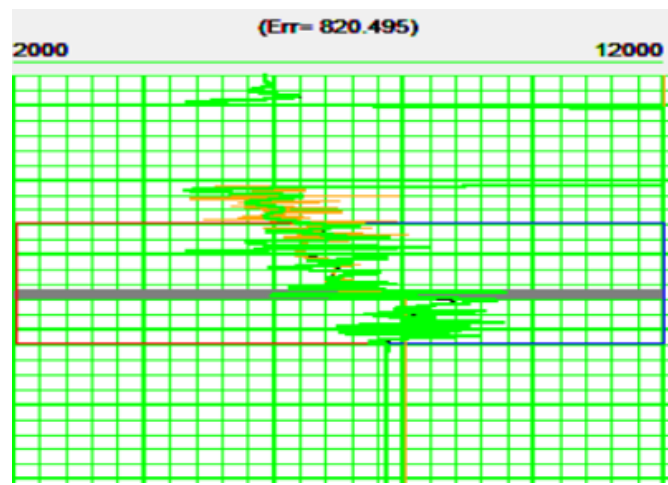

Fig. 13. Results of Inversion Analysis from Well FA-18 


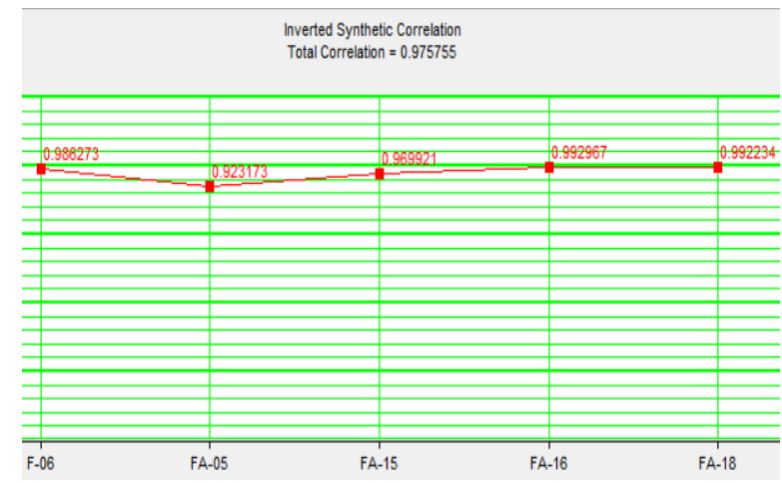

Fig. 14. Inversion correlation chart

In the multi-attribute stage, relationship between logs and seismic data is sought at the well location and this relationship used to predict or estimate the volume of the $\log$ properties at all locations in the seismic volume [5]. Inversion data will be used as an aid attribute for spreading data on a seismic map. Because this study wants to create a petrophysics reservoir model, the data included are only petrophysics data attributes such as porosity, water saturation, and shale content. This multi-attribute method can predict petrophysics values on the seismic from the well data held. A seismic attribute analysis were studied to estimate the physical properties such as porosity, permeability and others in a reservoir [6].

The beginning of this process is to enter seismic data, petrophysical wells, and inversion results as attributes. In the well data, water saturation, porosity, shale content, and permeability will use different attributes, because the usefulness of one attribute is not necessarily suitable for all data. It should be noted that when we determine the best combination of attributes to use in the final sum, the order of the attributes used may not be the same as the order of their correlation coefficients [7].

Attribute match will be seen from the error and correlation, so that we can determine which attribute correlation is good. In this study, Shale Content data were obtained using the attributes Amplitude Envelop, Derivative Instantaneous Amplitude, Amplitude Weithed Cosine Phase, Second Derivatice, and AI. Water Saturation data were obtained using the attributes Integrated Absolute Amplitude, Instantaneous Frequency, Apparent Polarity, Instantaneous Phase, and Second Derivative. Porosity data were obtained using the attributes of Instantaneous Phase, Second Derivative, AI, Quadrature Trace, and Integrate. If an attribute that matches the data being sought already exists, this attribute will be used to predict the data. In this study, the targeted multi-attribute correlation results were $\geq 0.5$, where the shale content data obtained a correlation of 0.57 , the water saturation data obtained a correlation of 0.73 , and the porosity data obtained a correlation of 0,52 . For multi-attribute compatibility, it can also be seen from the results of the crossplot of the wells (Figures 15 to Figure 17). Furthermore, a seismic section is made from the data sought. The multi-attribute results will also be matched to the seismic first, to see whether the distribution is good or not. The cross section should be displayed by passing the location of the well that is owned, therefore it is necessary to create an arbitrary line.

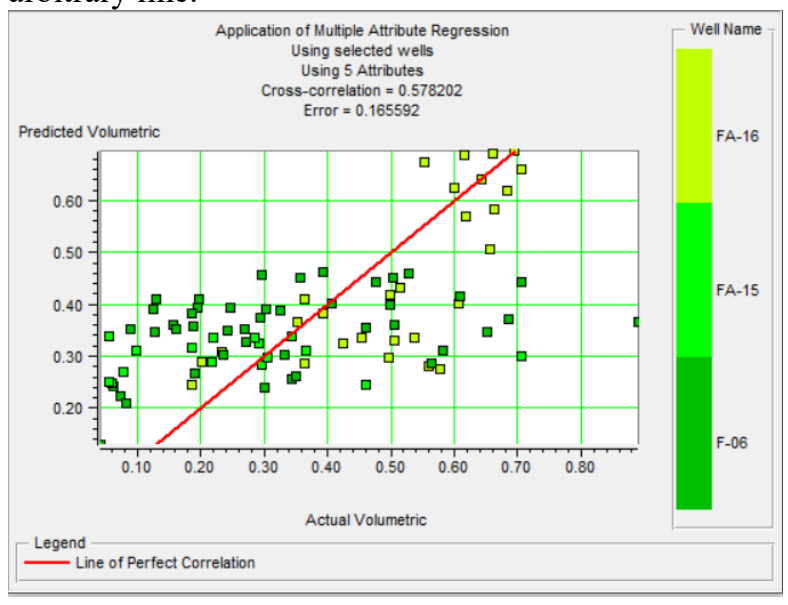

Fig. 15. Crossplot of Multiattribute Results on Shale Content

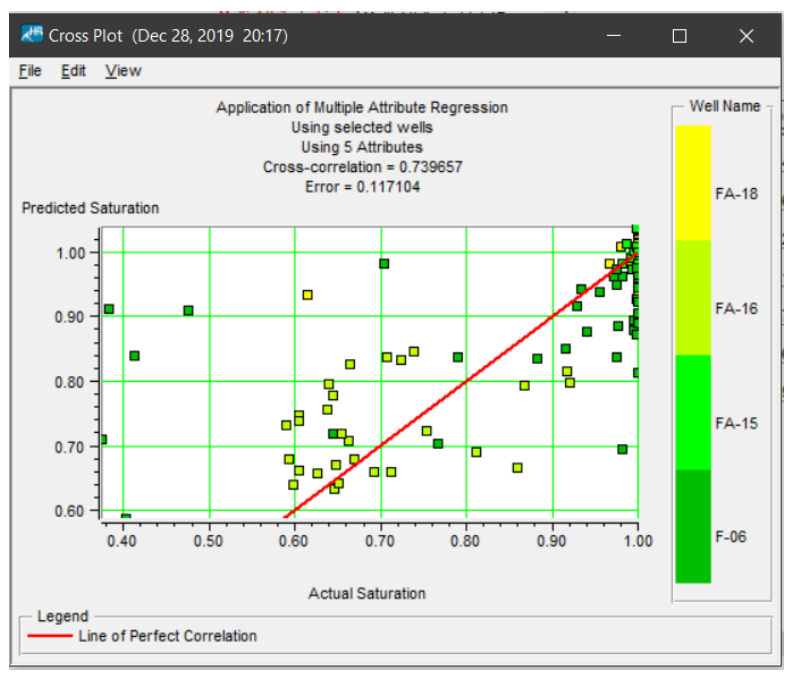

Fig. 16. Crossplot of Multiattribute Results on Water Saturation

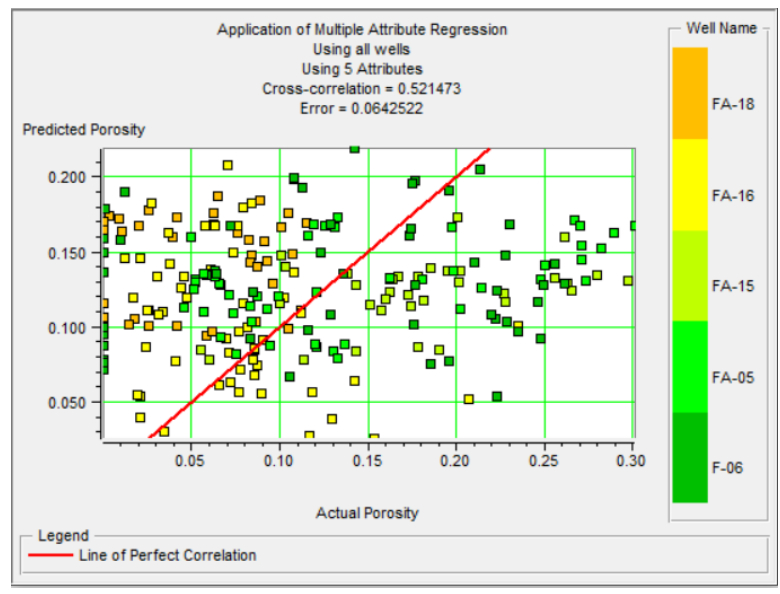

Fig. 17. Crossplot of Multiattribute Results on Porosity 


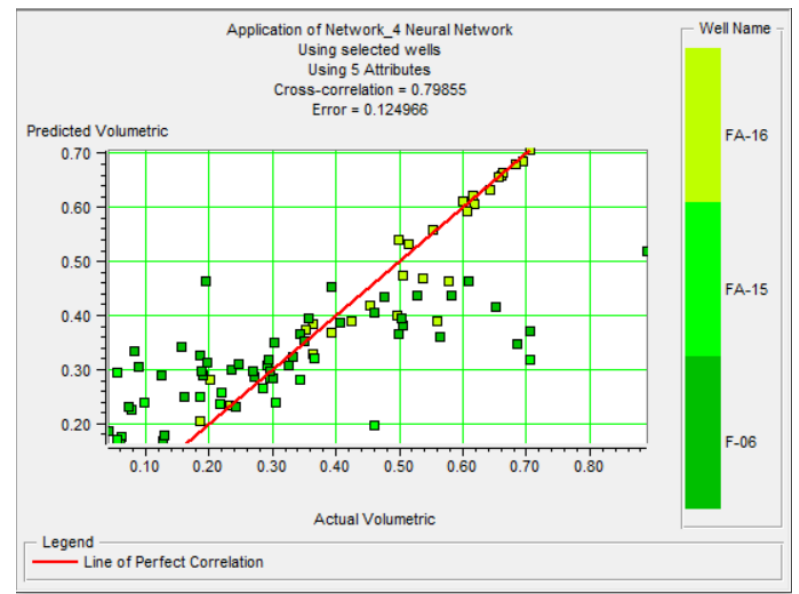

Fig. 18. Results of Crossplot Shale Content After Neural Network Process

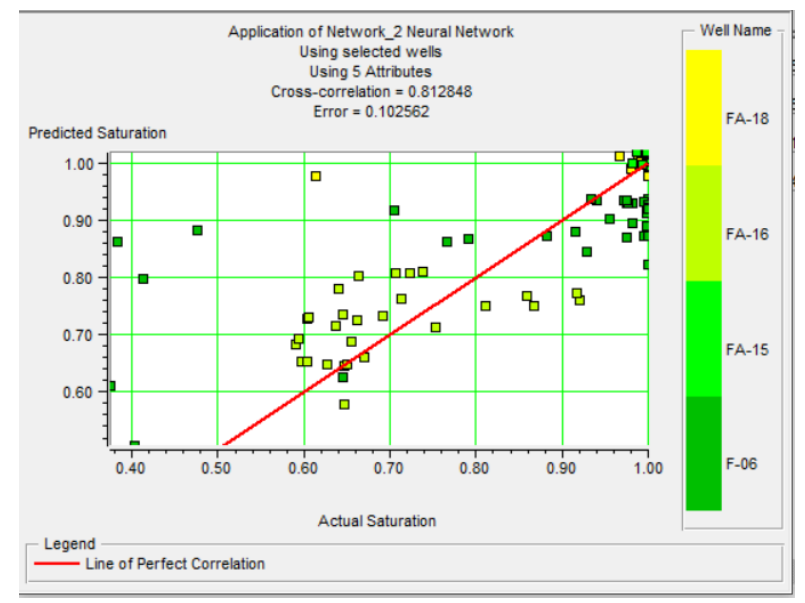

Fig. 19. Results of Crossplot Water Saturation After Neural Network Process

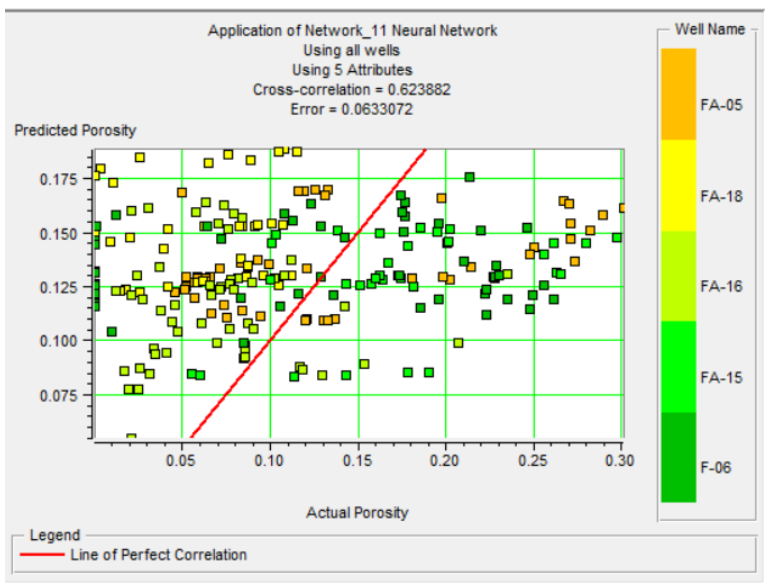

Fig. 20. Results of Crossplot Porosity After Neural Network Process

Probabilistic Neural Network method is needed to help spread these values. The Probabilistic Neural Network (PNN) is a mathematical interpolation scheme, to use a neural network architecture for its implementation [8]. This process will require data from the multi-attribute that we have used before, which is the multi-attribute process is to equate the output data with the data from the well. This PNN process will help this correlation so that it will produce similar output data on a seismic map.

To determine the area of hydrocarbons, modeling is needed in order to be able to determine the areas that contain hydrocarbon values that are good in modeling hydrocarbon data, it requires water saturation and porosity data. This cross-section will show the area and distribution of hydrocarbons in the reservoir

\section{Result and discussion}

In this research, reservoir targets are limited by $\mathrm{M}, \mathrm{N}$, and $\mathrm{O}$ horizons. To find out the hydrocarbons in the area, it is necessary to do a crossplot bounded by $\mathrm{M}, \mathrm{N}$, and $\mathrm{O}$ horizons on each well data. In the picture below the zone is divided into two colors, the red line is the sand zone and the black line is the shale zone. FA-05 data on Horizon M shows that there is a reservoir because the crossplots have sand zones, and there are zones that have good trends in sand and shale. Data on all wells on Horizon $\mathrm{N}$ and $\mathrm{O}$ also show reservoirs because the crossplots have sand zones, and there are zones that have good trends in sand and shale. At horizon M only uses FA- 05 well, because only the well has a good trend in its sand and shale. After that, the crossplot data is also made using a water saturation color key, in this data only the M horizon has good crossplot results because it can separate water and hydrocarbons. Meanwhile, at the $\mathrm{N}$ and $\mathrm{O}$ horizons the water and hydrocarbons are mixed, so zoning cannot be carried out.

The distribution of rock property data is generated from the neural network process. The neural network can search the relationship of input data with output data that is seismic rock property data. Neural Network that has been connected with input data, will be continued by spreading to other traces. The resulting rock properties produced are shale content, water saturation, and porosity. Here is a model of neural networks on shale content, water saturation, and porosity. Then the slice will be made from the model that has been made, to find out which areas can be reservoir areas.

Saturation data can indicate the presence of hydrocarbons, which is small saturation indicates the presence of hydrocarbons [9]. In the cross-section is shown below the reservoir target zone is not filled with water alone. The results of this will be sliced to see the distribution of each horizon. Horizon $\mathrm{M}$ has been given a box showing the potential hydrocarbon potential and the water saturation value is small (Figure 21), at horizon $\mathrm{N}$ and $\mathrm{O}$ the area also has a small water saturation area as well (Figure $22 \& 23$ ). So that the area given the box has the potential to have hydrocarbons. 


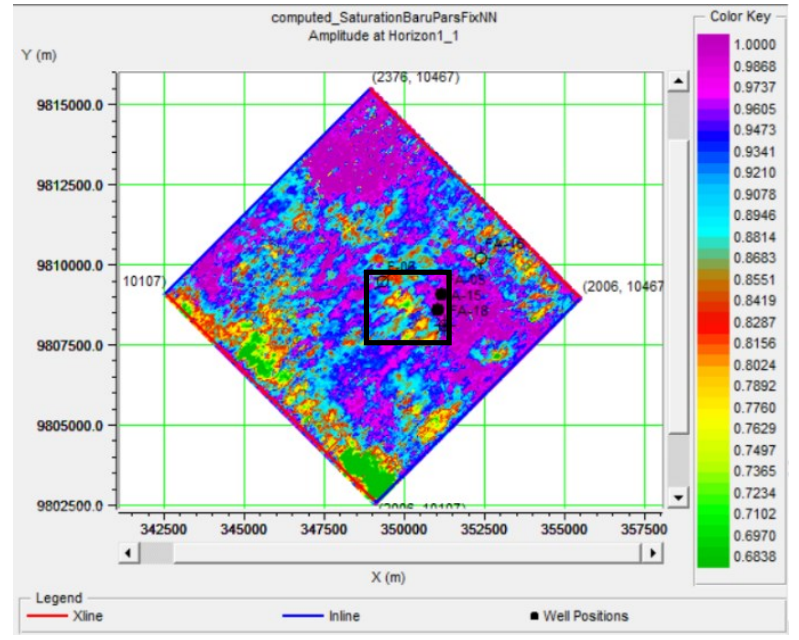

Fig. 21. Slice Horizon M on Water Saturation Data

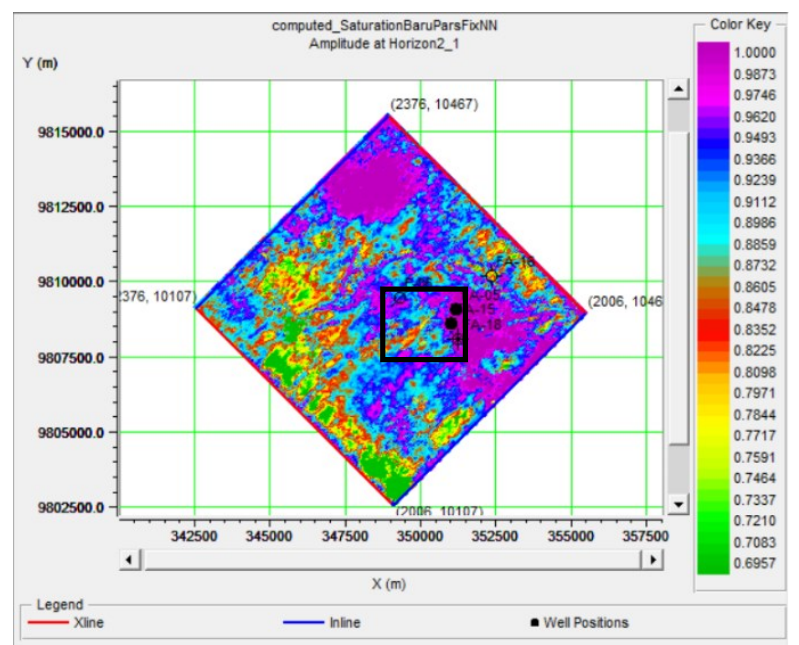

Fig. 22. Slice Horizon N on Water Saturation Data

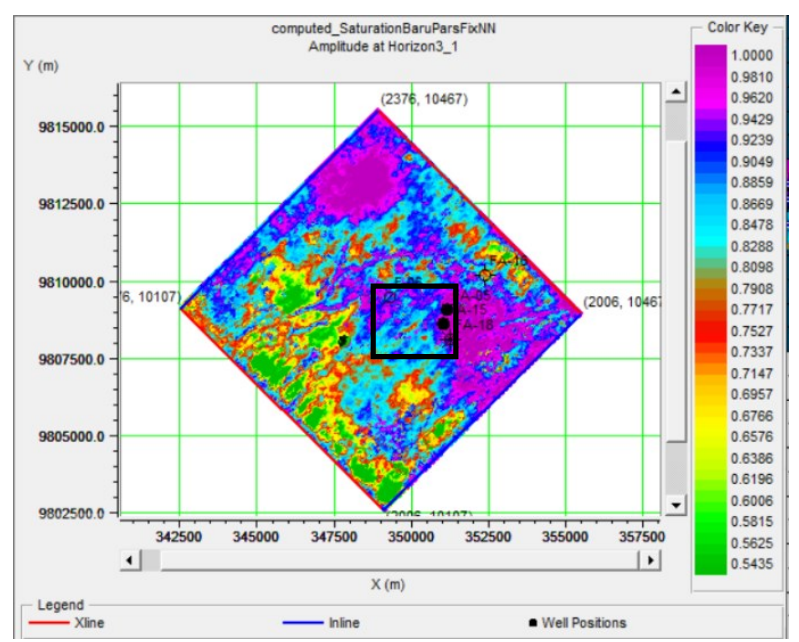

Fig. 23. Slice Horizon O on Water Saturation Data

From the water saturation data earlier, there are already areas that have hydrocarbon potential. However, additional data is still needed to ensure the existence of the hydrocarbons. This shale content data is used to find out which areas have good permeability and not. From this data, the data distribution looks good because the layers and the continuity are clearly visible. The results of the data will also be sliced to see the distribution in the $\mathrm{M}, \mathrm{N}$, and $\mathrm{O}$ horizons. At the $\mathrm{M}$ horizon, the area has shale content that is not too large (Figure 24), and from Horizon $\mathrm{N}$ the value decreases (Figure 25) and rises again at horizon $\mathrm{O}$ but the value is still not too large (Figure 26) So from these two data the area is still potential as a reservoir. The low shale content can assuming that this area is a clean formation [10].

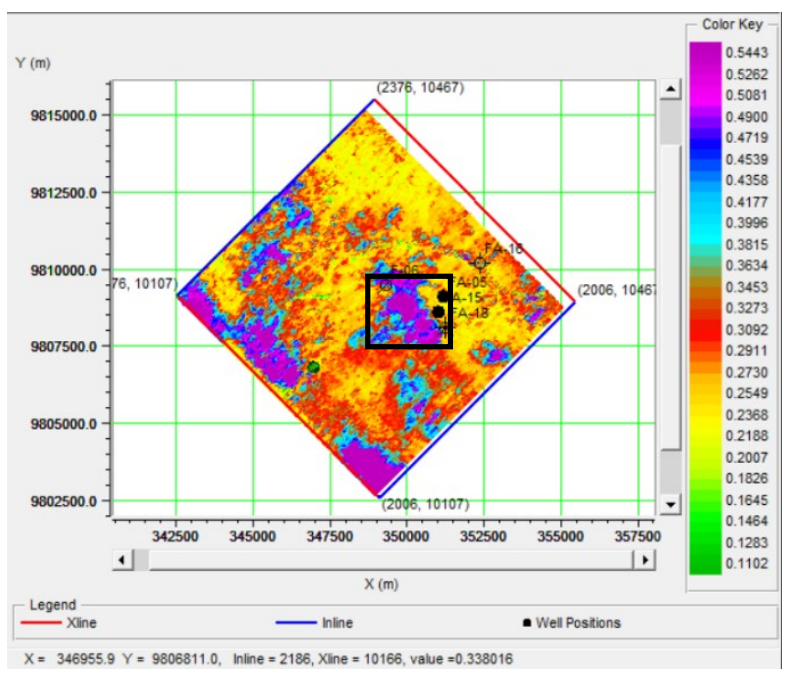

Fig. 24. Slice Horizon M on Shale Content Data

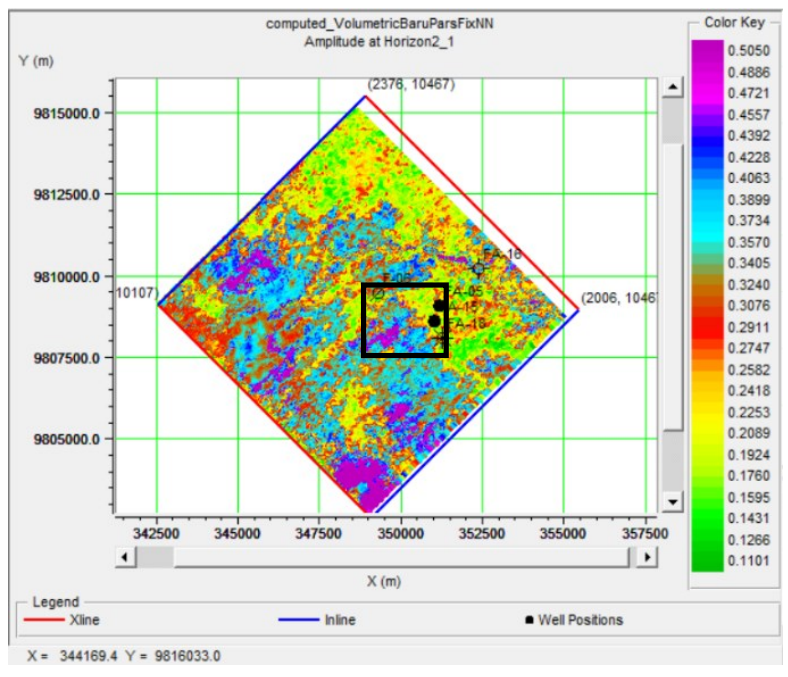

Fig. 25. Slice Horizon N on Shale Content Data

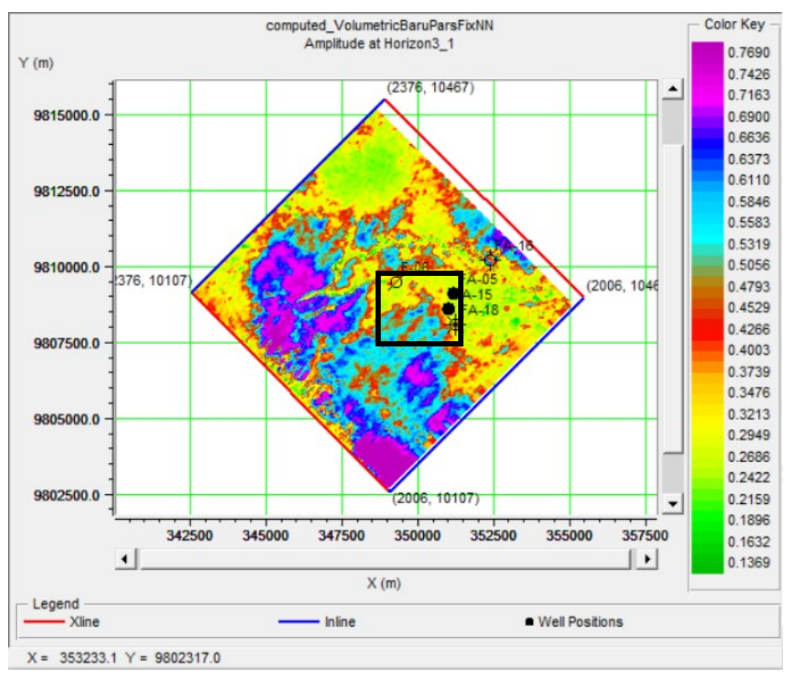

Fig. 26. Slice Horizon O on Shale Content Data 
Then from the porosity data, we can see how much the hydrocarbon value is contained. From the crosssection seen on the horizon there are areas that have high porosity. From the results of the slices on the horizon M, $\mathrm{N}$, and $\mathrm{O}$ the area also has a good porosity of the value $0.1-0.15$ (Figure 27-29).

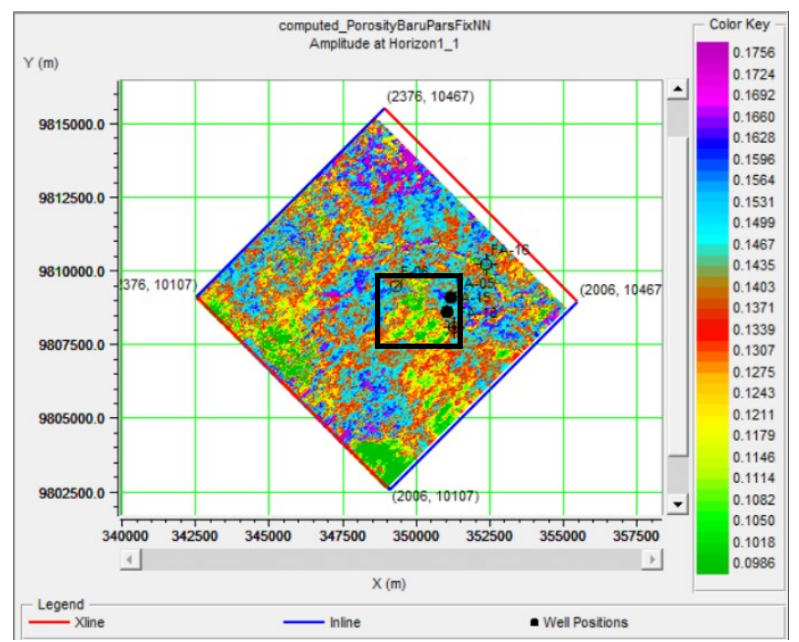

Fig. 27. Slice Horizon M on Porosity Data

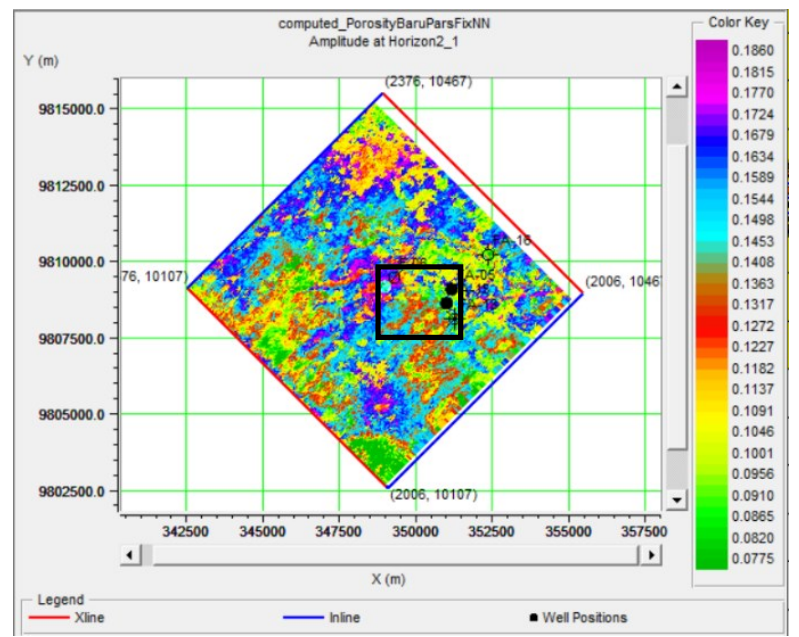

Fig. 28. Slice Horizon N on Porosity Data

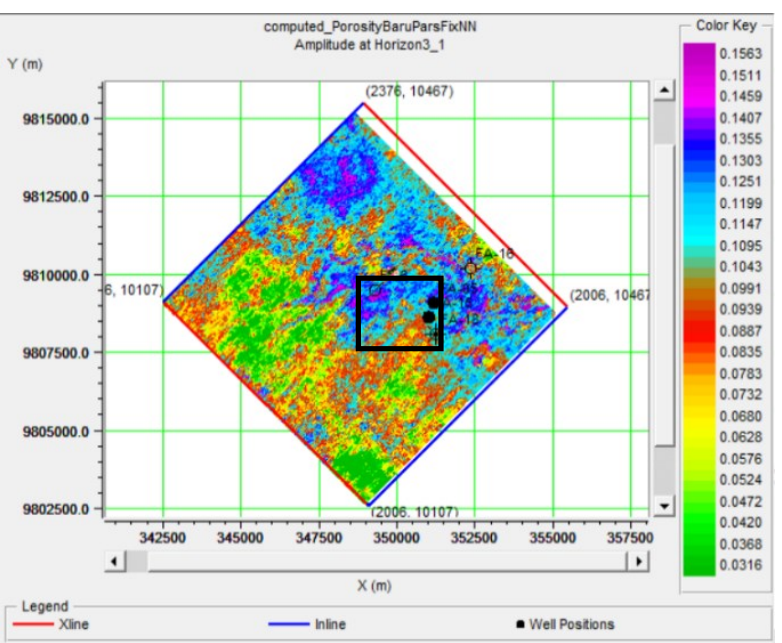

Fig. 29. Slice Horizon O on Porosity Data

The area given in the shape of the box in the figure is indicated as a reservoir. Where this area has a value of shale content that is not too large, small water saturation, and pretty good porosity. Where the low shale content indicates the rock is composed of sandstone. Water saturation data also shows that the area is not completely filled with water. These three characters support each other that the marked area can become a reservoir.

Hydrocarbon data is obtained from porosity and water saturation data. From this data we can see the hydrocarbon distribution directly. From the cross section, we can see that the hydrocarbons are in the horizon. From the slice results it also shows that the potential area also has hydrocarbons (Figure 30 - 32), the area was chosen because of the three porosity, water saturation, and shale content values indicate that the area has hydrocarbons and is also near the location of the well which the distribution of the area is better because the location of wells used is only in Inline $2195-2101$ and Xline 10308 - 10415. PPN techniques help to understand the distribution of the petrophysical parameters values and the detection of new drilling opportunities in this area [2].

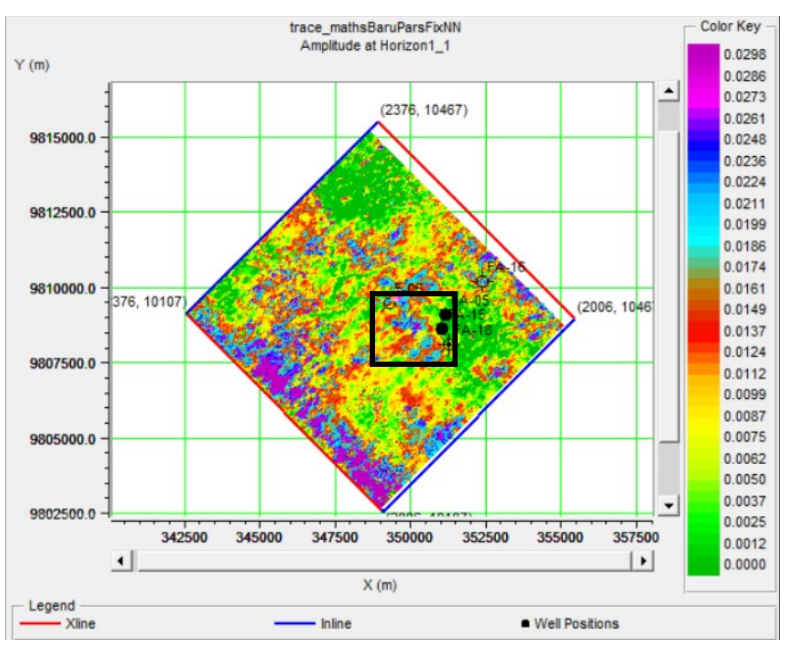

Fig. 30. Slice Horizon M on Hydrocarbon Data

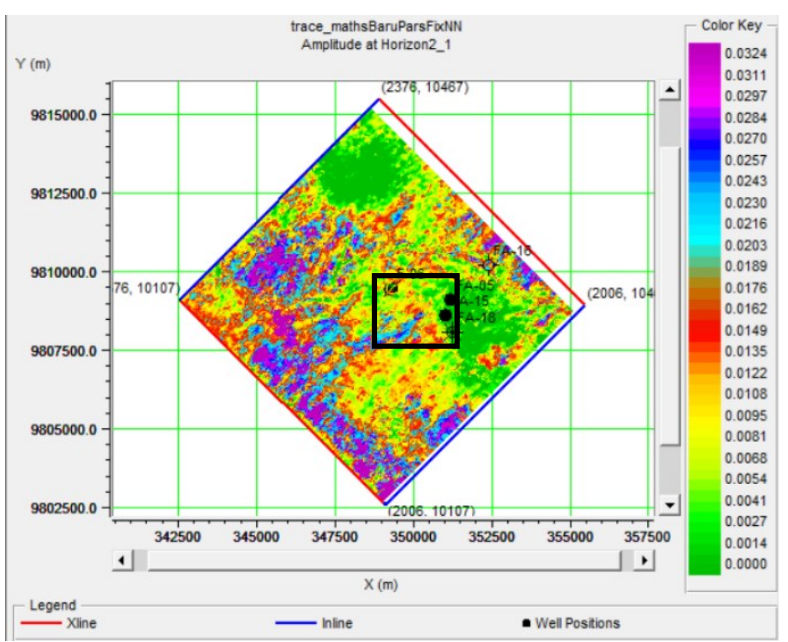

Fig. 31. Slice Horizon N on Hydrocarbon Data 


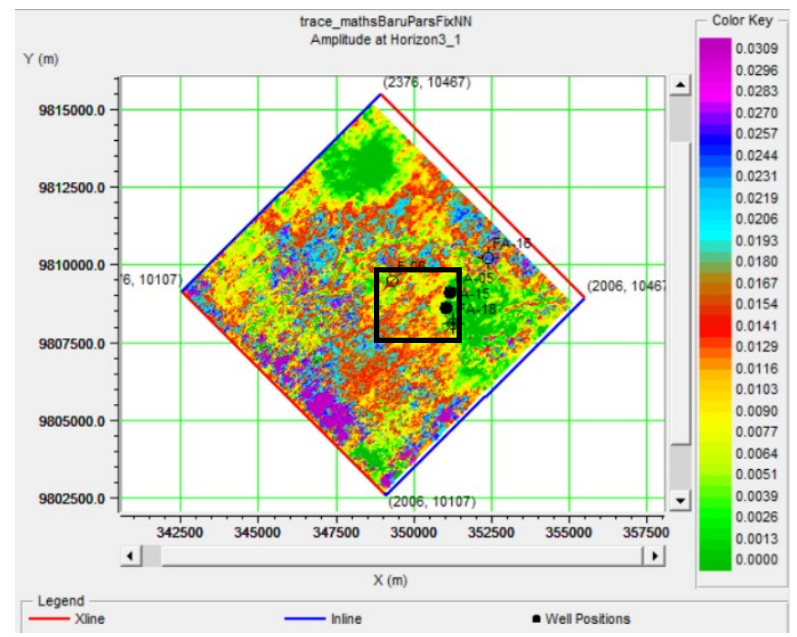

Fig. 32. Slice Horizon O on Hydrocarbon Data

\section{Conclusions}

Multi-attribute and neural network analysis can be used to determine predictions of porosity, water saturation, and shale content well and can be used for reservoir characterization. In this study, the results of multiattribute analysis on the prediction of shale content get a correlation value of 0.57 , the prediction of water saturation gets a correlation value of 0.73 , and the porosity of the correlation value obtained is 0.53 .

The porosity data, water saturation, and shale content show hydrocarbon presence in the reservoir between Well F-06, FA-05, FA-15, and FA-18 and continue to the west of Well FA-05, FA-15 and FA-18.

The addition of $\mathrm{Vp} / \mathrm{Vp}$ data and further porosity data can be used to confirm the content of reservoir. Another seismic attribute also can be used to support the rock properties in neural network process. More wells can also improve the accuracy of the hydrocarbon distribution map.

We would like to thank the Faculty of Mathematic and Natural Science of Universitas Indonesia for giving the permission to publish this study.

\section{References}

1. P.S. Schultz, S. Ronen, M. Hattori, C. Corbett, Seismic guided estimation of log properties, parts 1, 2, and 3: The Leading Edge, 13; 305-310; 674678; 770-776, (1994).

2. A.A.A. Othman, H.F. Ewida, M.A. Fathi, M.M.A.A. Embaby, Prediction of petrophysical parameters applying multi attribute analysis and probabilistic neural network techniques of seismic data for Komombo Basin, Upper Egypt. IJISET, (2015).

3. M.G. Bishop, South Sumatra Basin Province, Indonesia: The Lahat/Talang AkarCenozoic Total Petroleum System. Colorado: USGS, (2001).

4. D. Ginger, K. Fielding, The Petroleum System and Future Potential of The South Sumatra Basin.
Jakarta: Indonesian Petroleum Association, (2005).

5. Rachman, Pemetaan Distribusi Permeabilitas Berdasarkan Multiatribut dan Inversi Seismik (Studi Kasus Pada Daerah "XY”). Depok: Fakultas Matematika Dan Ilmu Pengetahuan Alam, (2009).

6. A. R. Brown, Interpretation of Three-Dimensional Seismic Data. Fourth Edition. American Association of Petroleum Geologists, (1996).

7. B. Russell, D. Hampson, J. Schuelke, J.A. Quirein, Multiattribute seismic analysis. Society of Exploration Geophysicists, (1997).

8. D. Hampson, J. Schuelke, J.A. Qurein, Use of Multi-Attribute Transforms to Predict Log Properties from Seismic Data. (2001).

9. M.K. Zain, Analisa Log Petrofisika dan Evaluasi Formasi Reservoar Pada Lapangan Boonsville. Depok: Fakultas Matematika Dan Ilmu Pengetahuan Alam, (2011).

10. H.J. Prawira, Karakterisasi Reservoar Lapangan ' $H$ ' Melalui Analisa Petrofisika dan Evaluasi Formasi, Depok: Fakultas Matematika Dan Ilmu Pengetahuan Alam, 2011. (2011) 